Revue d'histoire du XIXe siècle

Société d'histoire de la révolution de 1848 et des

révolutions du XIXe siècle

19 | 1999

Aspects de la production culturelle au XIXe siècle

\title{
Michel Offerlé [dir.], La profession politique, XIXe- XXe siècles, Paris, Belin, 1999, 360 p.
}

\section{Sylvie Aprile}

\section{OpenEdition}

\section{Journals}

Édition électronique

URL : http://journals.openedition.org/rh19/162

DOI : $10.4000 /$ rh19.162

ISSN : $1777-5329$

\section{Éditeur}

La Société de 1848

\section{Édition imprimée}

Date de publication : 1 décembre 1999

Pagination : 153-155

ISSN : 1265-1354

Référence électronique

Sylvie Aprile, " Michel Offerlé [dir.], La profession politique, XIXe-XXe siècles, Paris, Belin, 1999, 360 p. ». Revue d'histoire du XIXe siècle [En ligne], 19| 1999, mis en ligne le 26 août 2008, consulté le 22 septembre 2020. URL : http://journals.openedition.org/rh19/162 ; DOI : https://doi.org/10.4000/ rh19.162

Ce document a été généré automatiquement le 22 septembre 2020

Tous droits réservés 


\title{
Michel Offerlé [dir.], La profession politique, XIXe-XXe siècles, Paris, Belin, 1999, $360 \mathrm{p}$.
}

\author{
Sylvie Aprile
}

1 Cet ouvrage reprend en partie les communications d'une table ronde organisée lors du Ve congrès de l'Association française de science politique. Michel offerlé dans une introduction très suggestive présente les écueils et les modalités nouvelles de ces recherches. Il s'agit tout d'abord de sortir de l'étude hagiographique ou dénonciatrice de l'homme politique et de sa carrière. Par une recherche sur deux siècles, c'est tout d'abord aux variations sur le long terme que les contributions cherchent à révéler des variables concernant tout d'abord le recrutement. Peut-on dater ou du moins suivre le cheminement qui conduit à une professionnalisation du métier, un processus de " désencastrement " du politique par rapport au social?

Trois grands axes sont développés: les usages politiques des compétences professionnelles, les usages sociaux des fonctions politiques, les processus de légitimation.

Dominique Damanne retrace l'histoire des mots qui définissent depuis le XIXe siècle ce processus de professionnalisation. Il montre tout d'abord le rejet au XIXe siècle, du politicien de métier tant par la droite conservatrice qui souhaite que la ratification de l'autorité sociale reste évidente que par l'idéal républicain du désintéressement. L'idée même d'une rémunération est condamnée et renvoie à une situation clairement dénoncée, celle des politiciens américains, corrupteurs et clientélistes. C'est à travers l'émergence des enquêtes sociologiques, des travaux des politistes, des intellectuels et des hommes politiques eux-mêmes qu'il repère la banalisation d'une désignation qui s'est peu à peu imposée.

Éric Phélippeau s'attaque lui à l'opposition traditionnellement opérée entre notables et professionnels. Il montre à travers un exemple, celui du baron Arnaud de Mackau, qu'elle n'est pas aussi tranchée qu'il y paraît et qu'elle ne s'est pas achevée par la victoire d'un groupe sur un autre. Cette carrière qui se situe entre les années 1860 et la Première guerre mondiale montre les capacités d'adaptation d'un notable qui associe à 
un clientélisme traditionnel, les stratégies électorales les plus neuves. L'affichage, l'information, les relais témoignent d'un montage organisationnel militant où la compétence l'emporte sur la légitimité notabiliaire.

Mattei Dogan livre une synthèse de ses réflexions sur la carrière politique, analyse sur la longue durée allant de 1871 à 1993. Cette perspective montre une progressive fonctionnarisation du recrutement parlementaire. Le travail de Laurent Willemez nous montre l'intérêt que portent actuellement les politistes au XIXe siècle et surtout à la période de la Seconde République. Il revient lui aussi sur l'idée reçue qu'il conteste d'une entrée en politique des avocats en 1848. Il montre tout d'abord qu'il s'agit d'un mythe " utile " masquant d'autres univers et réseaux sociaux et privilégiant l'éloquence sur d'autres formes de compétence. Ces hypothèses sont étayées par une analyse statistique qui montre l'absence d'homogénéité de ce groupe professionnel et une évolution qui n'a rien d'une régulière progression: une fraction du barreau n'est pas l'ensemble des avocats.

Yves Déloye dans "Se présenter pour représenter" s'attache lui à l'analyse des professions de foi électorales de 1848. Ces actes de candidature sont un moyen d'inventorier les titres, les critères qui légitiment l'engagement politique. Il s'agit bien entendu d'en évaluer aussi la nouveauté. L'auteur répertorie un certain nombre de qualités requises ou revendiquées. C'est tout d'abord l'identification entre représenté et représentant qui est mise en avant. C'est la proximité géographique, professionnelle ou sociale. À ce modèle incarnatif s'adjoint progressivement un autre profil, celui de l'homme compétent, mais cette compétence est encore issue d'une légitimité professionnelle, celle des aptitudes juridiques ou économiques pour les notables, des capacités artisanales.

D'autres études sont centrées sur des pratiques qui intéressent plus directement le XXe siècle. On retiendra les travaux autour du codage et de l'étiquetage des activités politiques (Patrice Lehingue), des indicateurs de position sociale (Frédéric Sawicki), les conflits de légitimité (Jean-Louis Briquet).

Une même critique peut être formulée sur toutes ces contributions. Les auteurs ont tendance à puiser leur problématique dans la contestation de travaux anciens déjà largement disqualifiés par les recherches historiques les plus récentes. Ceci n'enlève rien à la qualité de leurs analyses mais il paraîtrait plus profitable d'entamer un dialogue entre politistes et historiens que de cheminer ainsi parallèlement. 